\title{
The Relationship Between Personality Characteristics Hardiness and Resiliency with the Academic Success of Operating Room Students
}

\author{
Imani Behzad ${ }^{1, *}$, Mosavi Nilofar ${ }^{2}$ \\ ${ }^{1}$ Department of Operating Room, Hamadan University of Medical Sciences, Hamadan, Iran \\ ${ }^{2}$ Student Research Committee, Hamadan University of Medical Sciences, Hamadan, Iran
}

Email address:

behzadiman@yahoo.com (B. Imani)

${ }^{*}$ Corresponding author

\section{To cite this article:}

Imani Behzad, Mosavi Nilofar. The Relationship Between Personality Characteristics Hardiness and Resiliency with the Academic Success of Operating Room Students. Higher Education Research. Vol. 4, No. 6, 2019, pp. 83-86. doi: 10.11648/j.her.20190406.12

Received: September 17, 2019; Accepted: September 29, 2019; Published: December 16, 2019

\begin{abstract}
Resiliency and hardiness can be mentioned in the characteristics of personality that psychologists have paid special attention to and which is referred to as indicators of mental health and quality of life. This is study cross-sectional descriptive-correlation study. The samples were undergraduate students in 2019. The findings showed a significant correlation between resilience and hardiness according to Pearson correlation coefficient. Also, there was a positive and significant relationship between hardiness and academic success. On the other hand, there was a positive and significant relationship between resilience and Academic Success and between resiliency and hardiness with There was a significant relationship between Academic Success.
\end{abstract}

Keywords: Hardiness, Resilience, Academic Success, Operating Room, Student

\section{Introduction}

Resilience is in fact the ability to overcome difficulties and overcome living conditions [1], and provides adaptation to a high level of balance in the threatening conditions of successful adaptation. Positive can be both a consequence of resilience and, as a precursor, a higher level of resilience [2]. Normal is able to think creatively and flexibly about problem-solving, meaning that he or she needs help from others when it is needed and is capable of solving problems for himself or herself. Resilient show a degree of health and independence. They are able to think and practice it, they can pass on their critical views to others, they have good feelings for those around them, and they believe in their ability to change their environment [3].

Thus, resiliency also involves positive change or growth, in addition to adaptation or problem-solving. Although some resilience-related traits are biologically and genetically determined, resilience skills can be taught and strengthened [4]. Resilience capacity is essential to succeed in the job [5], and in order to deal with occupational problems and mental health, individuals must skillfully develop resilience to overcome negative experiences and even bring those experiences into positive experiences [6,7]. People with high levels of psychological stubbornness do not perceive stressful job situations as stressful, so these challenges do not necessarily lead to stress and depression [8].

Due to their high self-esteem, stubborn individuals tend to emphasize positive events rather than negative events and increased stubbornness increases social self-esteem [9]. Bonanno (2015) identifies ways to gain resilience through hardiness, self-healing, suppressive coping, temperament, and positive emotions [10]. Resilience is a sign of resilience, which means how productive people are in difficult situations. People with high resilience are able to struggle and cope effectively in the face of stressful adverse events and events. Continue to succeed by going through the difficult stages of life [11]. Factors affecting multidimensional academic success are closely related to students' social, political, cultural, cognitive, and emotional development. Many scholars emphasize the influence of mental and cognitive abilities on Academic Success, but it should be noted that not 
only mental abilities affect Academic Success but also other factors [12].

On the other hand, students' academic success is one of the most important indicators in evaluating the higher education system, and all of its efforts and efforts are to cover it. In other words, society, and in particular higher education, is concerned and concerned about a person's destiny, successful development and position in society, and expects the individual in various aspects, including cognitive, skill, ability, and dimensions. His personality, emotions, and behavior, as they should, develop and excel [13]. Psychological capital is very important for college students, which can be considered as one of the most important elements of the higher education system, and if they have psychological capital, learning will be better and students will perform better [14].

\section{Materials and Methods}

This research was a descriptive-correlational crosssectional study that the researcher after sampling the research by the university ethics committee and obtaining the code of ethics sampled and conducted the research. At the time of the study, they were attending the Paramedical Faculty of Hamadan University of Medical Sciences and teaching hospitals for an internship; Data were collected through two questionnaires of Ahwaz Psychological Hardiness Questionnaire and Conor and Davidson Resiliency. The Ahvaz Psychological Hardiness Questionnaire consisted of 27 items that were used to rate this questionnaire: (Never $=0$ Rarely $=1$ Sometimes $=2$ Often $=3$ ) Except for Articles 21, $17,13,10,7,6$ were negative and scored in reverse. The range of scores ranged from 0 to 81 . The high score on the Hardiness Questionnaire indicates high psychological hardiness in the individual. Conor \& Davidson Resilience Scale consisted of 25 items that were used to score a 5-point
Likert scale (completely false $=0$ rarely $=1$ sometimes true $=$ 2 often true $=3$ always true $=4$ ). To determine the validity of this scale, the first correlation of each score with the total score except for item 3 showed coefficients between 0.41 0.64 and Cronbach's alpha method was used to determine the reliability. The reliability coefficient was 0.89 . The criterion of Academic Success in this study was based on the mean score of students in two groups with an average score of 17 and above (successful students) and under 17 (unsuccessful students). Data were analyzed using the Pearson correlation coefficient, linear regression analysis, and ANOVA and SPSS software version 23 .

\section{Findings}

In this study, 103 undergraduate students of Hamadan University of Medical Sciences participated, 57 (55\%) were female and $46(45 \%)$ were male. Most of the subjects were 21-24 years (71\%). 11 (11\%) were married and $92(89 \%)$ were single. Most of the respondents were Shiites (96\%) and most of them had family members of 4 and less (53\%). Most of the subjects were in a dormitory (45\%). Also, most of the subjects were in the fifth semester $(38 \%)$.

On the other hand, there was a significant relationship between hardiness with demographic information such as marital status, residence, and semester, but there was no significant relationship between hardiness with gender, age, religion and number of family members. Also, there was a significant relationship between resilience and demographic information (marital status, residence, and semester) but no significant relationship between resilience with gender, age, religion and number of family members. There was a significant relationship between residence and semester, but there was no significant relationship between Academic Success, religion, and the number of family members (Table 1).

Table 1. Pearson's correlation coefficient test between demographic information with hardiness, resilience, and Academic Success.

\begin{tabular}{llll}
\hline Variable statistics & Academic Success & resilience & hardiness \\
\hline \multirow{2}{*}{ Gender } & $\mathrm{r}=-0 / 751$ & $\mathrm{r}=0 / 103$ & $\mathrm{r}=-0 / 123$ \\
& $\mathrm{p}=0 / 029$ & $\mathrm{p}=0 / 973$ & $\mathrm{p}=0 / 817$ \\
Age & $\mathrm{r}=-0 / 118$ & $\mathrm{r}=0 / 088$ & $\mathrm{r}=0 / 145$ \\
& $\mathrm{p}=0 / 237$ & $\mathrm{p}=0 / 379$ & $\mathrm{p}=0 / 654$ \\
Marital status & $\mathrm{r}=0 / 732$ & $\mathrm{r}=0 / 743$ & $\mathrm{p}=0 / 759$ \\
& $\mathrm{p}=0 / 045$ & $\mathrm{p}=0 / 038$ & $\mathrm{r}=0 / 571$ \\
Religion & $\mathrm{r}=-0 / 743$ & $\mathrm{r}=-0 / 119$ & $\mathrm{p}=0 / 447$ \\
Number of family members & $\mathrm{p}=0 / 149$ & $\mathrm{p}=0 / 851$ & $\mathrm{r}=0 / 119$ \\
& $\mathrm{r}=-0 / 143$ & $\mathrm{r}=-0 / 123$ & $\mathrm{p}=0 / 928$ \\
semester & $\mathrm{p}=0 / 148$ & $\mathrm{p}=0 / 979$ & $\mathrm{r}=0 / 748$ \\
& $\mathrm{r}=-0 / 708$ & $\mathrm{r}=0 / 830$ & $\mathrm{p}=0 / 027$ \\
\hline
\end{tabular}

The results also showed a significant positive relationship between students' hardiness and Academic Success $(r=0.864, p$ $<0.001$ ) (Table 2).

Table 2. Pearson correlation coefficient test between hardiness and Academic Success.

\begin{tabular}{llc}
\hline Variable statistics & Pearson correlation coefficient & The significance level \\
\hline $\begin{array}{l}\text { Academic Success } \\
\text { Hardiness }\end{array}$ & $\mathrm{r}=0 / 864$ & $\mathrm{P}<0 / 001$ \\
\hline
\end{tabular}


On the one hand, there is a positive and significant relationship between resiliency of students with their Academic Success $(\mathrm{r}=0.78, \mathrm{p}<0.001)$ (Table 3$)$.

Table 3. Pearson correlation coefficient test between resilience and Academic Success.

\begin{tabular}{lll}
\hline Variable statistics & Pearson correlation coefficient & The significance level \\
\hline Academic Success & $\mathrm{r}=0 / 78$ & $\mathrm{P}<0 / 001$ \\
Resilience & & \\
\hline
\end{tabular}

According to the findings, there was a significant relationship between hardiness and resilience of students with their Academic Success $(\mathrm{p}=0.001)$ (Table 4$)$.

Table 4. Linear Regression Coefficient Test and ANOVA Test for Hardiness and Resilience with Academic Success.

\begin{tabular}{llc}
\hline Variable statistics & Linear Regression Coefficient (ANOVA) & The significance level \\
\hline Hardiness & $\mathrm{F}=28 / 8$ & $\mathrm{P}=0 / 001$ \\
Resilience & & \\
Academic Success & & \\
\hline
\end{tabular}

Results also showed a significant relationship between students' hardiness and their resilience $(p=0.001)($ Table 5).

Table 5. Pearson correlation coefficient test between hardiness and resilience.

\begin{tabular}{lll}
\hline Variable statistics & Pearson correlation coefficient & The significance level \\
\hline Hardiness & $\mathrm{r}=0 / 845$ & $\mathrm{P}=0 / 001$ \\
Resilience &
\end{tabular}

\section{Discussion}

The average student resilience score was 63.66, which indicates high student resilience. Also, the mean score of the stubbornness of the students was 50.49, which is also a factor for students. Similarly, in the study of Abrishamkesh et al. (2016), which is the relationship between psychological hardiness and resilience with mental health in pre-hospital emergency technicians in Guilan province, the mean resilience score was 27.55 and the mean resilience score was 78.15. This has been shown to reflect the high resilience and low hardiness of pre-hospital emergency technicians, which is inconsistent with the results of this study [15]. In Yazdani's (2012) study, which examines the relationship between hardiness and fitness characteristics with Academic Success in Army Medical University students in 2012, the mean resiliency score was 41.59 and the mean toughness score was 13.49. There is a high degree of resilience and hardiness of the students that are in line with the results of this study [16]. There was a significant relationship between resilience and hardiness according to Pearson correlation coefficient $(p=0.001)$. In this regard, Mirzamohammadi et al. (2016) in their study, which is related to parenting styles and psychological hardiness with resilience in students, showed that the relationship between resilience rate of Kermanshah girls' high schools and students Their psychological hardiness is direct and significant ( $\mathrm{p}$-value $<0 / 01$ which is consistent with the results of this study [17]. Also in the study of Georgoulas-Sherry and Kelly (2019), Resilience, Resistance and Hardiness: Define the relationships between these structures through structural equation modeling techniques based on a sample of 1205 from the US Military Academy. Show the resilience, strength, and hardiness was positively correlated $(\mathrm{p}<0 / 001)$, which is consistent with the results of this study [18].

According to Pearson correlation test, there is a positive and significant relationship between hardiness and Academic Success $(r=0.64)(p<0 / 001$ in the Norouzi et al. (2016) study, which was predicted by head perception difficulty). Success and emotion regulation in martial athletes is good. Results show that there is a relationship between hardiness with perception of success $(r=0.22)$, reappraisal $(r=-0.44)$ and depression $(r=-0 / 50)$. There is a significant and increasing perception of athletic success that increases athletes' stubbornness [19]. Also, according to Pearson correlation test, there is a positive and significant relationship between resilience and Academic Success $(r=0.78)$, $p$ $<0 / 001$ (in the study of Akbarilakeh et al. (2017), which is the relation of resilience to Academic Success in dental students of Shahid Beheshti University of Medical Sciences, 2015-95, between resilience score and basic science score as a criterion for Academic Success. A significant positive and direct correlation was observed $(\mathrm{P}<0 / 001$, OR $=14)$, which is in agreement with the results of this study [20]. There is a significant relationship $(\mathrm{p}=0.001)$ with Academic Success that Rostami et al. (2015) in their research titled the relationship between hardiness, resilience, and burnout among network health workers. There is no significant relationship between resilience and stubbornness with lack of personal success $(r=0.087)$, which is in agreement with the results of this study [21].

\section{Conclusion}

The two personality traits of hardiness and resilience in enhancing students' academic achievement in this study are quite evident. The greater the resilience and tenacity of the 
students, the greater the academic success of the students. So what's important is that by increasing resiliency skills, you can increase students' academic success. At the same time, by enhancing the hardiness of the features, the educational capabilities can be increased.

\section{Conflict of Interest}

There is no conflict of interest among the authors.

\section{Acknowledgements}

We are grateful to the Vice-Chancellor for Research and Technology of Hamadan University of Medical Sciences, which supported the research project of this study with the Code of Ethics (IR.UMSHA.REC.1397.442).

\section{References}

[1] Sagone E, De Caroli M. A Correlational Study on Dispositional Resilience, Psychological Well-being, and Coping Strategies in University Students. American Journal of Educational Research. 2014; 2 (7): 463-471. DOI: 10.12691/education-2-7-5.

[2] Karatas Z, Akif Ersoy M. Self-Esteem and Hopelessness, and Resiliency: An Exploratory Study of Adolescents in Turkey. International Education Studies. 2011; 4 (4): 84-91. DOI: 10.5539/ies.v4n4p84.

[3] Alvord CB, Bogar CB, Hulse-Killacky D. Resiliency Determinants and resiliency processes among female adult survivors of childhood sexual abuse. Journal of Counseling \&

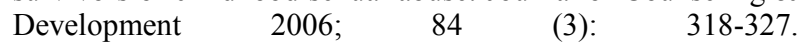
https://doi.org/10.1002/j.1556-6678.2006.tb00411.x.

[4] Froneman K, Du Plessis E, Koen MP. Effective educatorstudent relationships in nursing education to strengthen nursing students' resilience. Curationis. 2016, 10; 39 (1): e1e9. DOI: 10.4102/curationis.v39i1.1595.

[5] Kolsoum D, et al. The Relationship between Resiliency and Burnout in Iranian Nurses: A Systematic Review and MetaAnalysis. Maced J Med Sci. 2018 Nov 25; 6 (11): 2250-2256. DOI: $10.3889 /$ oamjms.2018.428.

[6] Warelow $\mathrm{Ph}$, Edward, Karen-liegh. Caring as a resilient practice in mental health nursing. International Journal of Mental Health Nursing 2007; 16 (2): 132-135. DOI: 10.1111/j.1447-0349.2007.00456.x

[7] Maddi, S. R. (2014). Hardiness leads to meaningful growth through what is learned whenresolving stressful circumstances In P. Russo-Netzer (Ed.), Meaning in positive and existential psychology. (pp. 271). New York, New York: Springer Science+Business Media. DOI: 10.1007/978-1-4939-03085_17.

[8] Dibaji, S. M. Oreyzi Samani, S. H. \& Abedi, M. (2017). The Mediating Role Of Psychological Hardiness And Extraversion In The Relationship OfJob Demands With Stress And Depression Of Working Men. Iran Occupational Health Journal, 14 (3): 105-16.

[9] Shian Ghohrood, H. Comparative study of relationship between selfesteem and psychological hardiness with selfefficacy in blind and normal girl students of middle school in Tehran. PhD. thesis, Allameh Tabataba'i University, 2012. [Persian].

[10] Bonanno A. Loss, trauma, and human resilience: Have we underestimated the human capacity to thrive after extremely aversive events? Psychological Trauma: Theory, Research, Practice, and Policy. 2015; 8 (1): 35-46. DOI: 10.1037/0003066X.59.1.20.

[11] Southwick SM, Bonanno GA, Masten AS, Panter-Brick C, Yehuda R. Resilience definitions, theory, and challenges: interdisciplinary perspectives. Eur J Psychotraumatol 2014; 5 (10): 1-10. https://doi.org/10.3402/ejpt.v5.25338

[12] Mohammadi Y, Kazemi S, Hajabadi M, Raisoon MR.[The relationship between physiological learning styles, creativity, and Academic Success among students at Birjand University of Medical Sciences during the academic year 2013-2014]. MODERN CARE JOURNAL 2015, Volume 11, Number 4; Page(s) 275 To 282. [Persian]

[13] Raeisoon MR, Mohammadi Y, Abdorazaghnejad M, Sharifzadeh Gh. [An investigation of the relationship between self-cncept, self-esteem, and Academic Success of students in the nursing-midwifery faculty in Qaen during 2012-13 academic year]. Mod Care J 2014; 11 (3): 236-42. [Persian]

[14] Wen M, Lin D. Does Psychological Capital Combat Learning and Adaptive Stress of College Freshmen. Journal of Studies in Education 2014; 4 (1): 25-42. DOI: https://doi.org/10.5296/jse.v4 i1.4684

[15] Abrishamkesh S, Ardalan A, Kafi Masoleh SM, Fallahi Khesht Masjedi M. Relationship of Psychological Hardiness and Resilience with the Mental Health in Pre-Hospital Technicians, Guilan Province. Journal of Holistic Nursing And Midwifery. 2016; 82: 10-18.

[16] Yazdani, A. Relationship of hardiness personal characteristics and residency with educational success in students of Aja University of Medical Science. PhD Thesis. Aja University of Medical Science, 2012. [In Persian] doi: 10.1097/ALN.0000000000000232.

[17] Mirzamohammadi Z, Mohsenzadeh F, Arefi M. The Relationship between Parenting Styles and Psychological Hardiness with Resilience in Students. Family and Research. 2016; 13 (33): 97-119.

[18] Georgoulas-Sherry V, Kelly D. Resilience, Grit, and Hardiness Determining the Relationships amongst these Constructs through Structural Equation Modeling Techniques. Journal of Positive Psychology \& Wellbeing, 2019.

[19] Norouzi H, Shahhosseni M, Golmohammadi B. Prediction of Hardiness Among Elite Epic Athletes According to Perception of Success and Emotion Regulation. Journal of Medical Sciences of Zanko. 2016; 17 (55): 55-67.

[20] Akbarilakeh M, Eftekharzadeh T, Khodakarim S. Relationship between resilience and academic success in dental students of Shahid Beheshti University of Medical Sciences, 2015-16. Journal of Health in the Field. 2017; 5 (3): 41-48.

[21] Rostami Ch, et al. The Relationship between Hardiness, Resilience, and Job Burnout among Health Workers of the Health Network of the City of Kamyaran. Shenakht Journal of Psychology and Psychiatry. 2015; 2 (1): 1-12. 